\title{
Application Value of Contrast-Enhanced Ultrasound In The Diagnosis of Intermediate Trophoblastic Tumours
}

\author{
XiaoDan Zhu \\ The First Affiliated Hospital of Zhejiang University School of Medicine \\ Yin Hu \\ The First Affiliated Hospital of Zhejiang University School of Medicine \\ LinYu Zhou \\ The First Affiliated Hospital of Zhejiang University School of Medicine \\ TianAn Jiang ( $\nabla$ tiananjiang@zju.edu.cn ) \\ The First Affiliated Hospital of Zhejiang University School of Medicine
}

\section{Research Article}

Keywords: Contrast-enhanced ultrasonography (CEUS), Colour Doppler ultrasound image (CDFI), Placental-site trophoblastic tumour (PSTT), Epithelioid trophoblastic tumour (ETT), Intermediate trophoblastic tumours (ITTS).

Posted Date: January 4th, 2022

DOI: https://doi.org/10.21203/rs.3.rs-138492/v2

License: (c) (i) This work is licensed under a Creative Commons Attribution 4.0 International License. Read Full License 


\section{Abstract}

Background: As the rarest gestational trophoblastic neoplasia (GTN), intermediate trophoblastic tumours (ITTs) are very difficult to diagnose before surgery due to the lack of specificity of clinical manifestations. Routine colour Doppler ultrasonography is currently the simplest and reproducible imaging method for diagnosing ITTs, but it is not as specific as other tumours. Through the research and analysis of colour Doppler ultrasound images (CDFI) and contrast-enhanced ultrasonography (CEUS) images of ITTs, the ultrasound characteristics and CEUS perfusion characteristics are summarized, and these findings can provide a reference for the correct diagnosis of ITTs.

Methods: Seven ITT patients were diagnosed and treated in our institution from January 2016 to August 2020, and the clinical data of all patients were retrospectively collected and analysed. Two sonographers who had worked for more than 5 years analysed the characteristics of the ultrasound and CEUS. Among them, the characteristics of CEUS are summarized and analysed from the four aspects of contrast enhancement method, time, boundary, and intensity. All cases were diagnosed with pathological support by ITTs.

Results: The most common clinical symptoms of ITT are vaginal bleeding and amenorrhea. The serum ß-human chorionic gonadotropin (serum-hCG) level was mainly a low-grade increase, but to determine whether the serum-hCG level can be used as one of the indicators for monitoring ITT recurrence or metastasis, a large sample data analysis is needed. The lesion location, internal echo changes, and blood flow signals of ITTs were not significantly specific compared with those of other GTNs. However, the CEUS performance of ITTs has certain characteristic changes, in which the enhancement mode was mainly regional enhancement, the arterial phase showed slow, equal-slightly high enhancement, and the enhanced bounders were not very clear. Compared with the CEUS performance of other GTNs, it has a certain specificity.

Conclusions: Certain characteristic changes in CEUS of ITTs, combined with clinical features, can provide help for the accurate diagnosis of ITT.

Trial registration: For non-clinical or non-health care intervention on human participants of what the article reports.

\section{Background}

Gestational trophoblastic neoplasia (GTN) is a series of benign and malignant pregnancy diseases. Benign lesions include placental nodules and placental site exaggeration, and neoplastic lesions include choriocarcinoma (CC), placental site trophoblastic tumour (PSTT) and epithelioid trophoblastic tumour (ETT). Both PSTTs and ETTs are derived from intermediate trophoblast cells in the planting part of the placenta. However, PSTTs are derived from planting intermediate trophoblast cells, and ETTs are derived from villous intermediate trophoblast cells ${ }^{[1]}$. Both have similar biological behaviours and clinical characteristics. In 2014, the World Health Organization (WHO) gynaecological tumour pathology classification classified ETTs and PSTTs as ITTs. ITTs are the rarest type of GTN, with an incidence of approximately $1 \%-2 \%$ [1].

ITTs mainly occur in women of childbearing age, but there are also reports of postmenopausal patients with ITTs. ITTs can be secondary to multiple pregnancy outcomes, including full-term pregnancy, miscarriage, ectopic pregnancy and molar pregnancy ${ }^{[2-3]}$. The time of onset varies from the length of the previous pregnancy. The clinical manifestations of ITTs are usually nonspecific. Amenorrhea and irregular vaginal bleeding are the most common symptoms ${ }^{[1]}$. Some patients may not have any clinical manifestations, and ITTs are found during physical examination. Unlike other GTNs, which are highly aggressive, most ITTs have a good clinical course and slow progression. PSTTs are confined to the uterus for a long time, and most of them do not easily metastasize; therefore, the prognosis is good. The most common metastatic sites are the lung, liver and vagina ${ }^{[4-6]}$. ETT grows slowly, but some cases are highly aggressive, and the clinical outcome can be fatal ${ }^{[7]}$. ETTs are mainly concentrated in the lower part of the uterus and cervix, and there are also extrauterine metastases, such as vagina, broad ligament, and fallopian tube, and even to the lungs and liver ${ }^{[8]}$. Due to the lack of specific clinical manifestations of ITTs, preoperative diagnosis of ITTs is very difficult, which can easily lead to misdiagnosis. The treatment plan and clinical outcome of ITTs are quite different from those of other GTNs. Therefore, early diagnosis is essential for choosing a reasonable treatment plan and improving patient prognosis.

Little is known about the ultrasound characteristics of ITTs. In 1991, Caspi et al. ${ }^{[9]}$ described the ultrasound appearance of a PSTT for the first time. It was a local lesion of the myometrium with a honeycomb cystic area, which was difficult to distinguish from the ultrasound appearance of the invasive hydatidiform. Savelli et al. ${ }^{[10]}$ reported the first case in which PSTT was suspected and confirmed by surgery during transvaginal ultrasonography (TVS). They believed that the lesion had heterogeneous and unclear borders and scattered blood flow. There are also cases showing that PSTT can lead to the formation of uterine arteriovenous fistulas ${ }^{[11]}$, but there is a lack of real ultrasound research. In 2013, Zhou et al. ${ }^{[12]}$ reviewed the ultrasound findings of 14 patients with PSTT. According to the location and characteristics of the lesion, these cases were divided into heterogeneous solid lesions in the uterine cavity with minimal to moderate blood flow signals, muscular heterogeneous solid lesions with minimal to abundant blood flow signals and cystic areas of the myometrium with abundant blood flow signals. Some studies believe that ultrasound images of ETTs appear as a single heterogeneous echogenic nodule of different sizes in the myometrium of the uterus and/or cervical canal, with clear boundaries and minimal blood flow signals ${ }^{[13]}$. In 2014, Qin et al. ${ }^{[14]}$ retrospectively analysed the ultrasound images of 12 patients with ETT and concluded that the abundant blood flow signals around the lesion are a characteristic change in ETTs.

Colour Doppler ultrasound is currently the simplest and reproducible imaging method for diagnosing ITTs, but it is not highly specific compared to other tumours. Colour Doppler ultrasound can provide a good understanding of tumour size, location, morphological contour, internal structure and relationship with surrounding tissues. However, due to the poor ability of this technology to display low-velocity blood flow and a certain angle

Page $2 / 10$ 
dependence, it is not ideal for imaging small blood vessels and low-velocity blood flow in tumours and cannot meet the requirements for imaging tumour neovascularization. CEUS is a technology that uses contrast agents to enhance the backscatter echo, thereby significantly improving the resolution, sensitivity and specificity of ultrasound diagnosis ${ }^{[15]}$. This technology is currently the latest method of displaying vascular perfusion, which can significantly improve the ability to display small blood vessels and low-velocity blood flow in tumours. At present, CEUS is mostly used in the diagnosis of gynaecological tumours, and there are no reports on using CEUS to diagnose ITTs. The main purpose of this study was to review the clinical manifestations of ITTs, study and analyse colour Doppler ultrasound and CEUS images, and summarize the characteristics of ultrasound and CEUS perfusion to provide references for the correct diagnosis of ITTs.

\section{Methods}

Patients with a suspected ITT were enrolled from January 2016 to August 2020 at the First Affiliated Hospital, Zhejiang University School of Medicine, and there were a total of 13 patients. Inclusion criteria included serum hCG positivity; uterine or pelvic lesions and willingness to undergo CEUS examination. The exclusion criteria were as follows: mass cornual pregnancy, incisional pregnancy, intramuscular pregnancy, and residual pregnancy products diagnosed by routine ultrasound; and a history of drug allergy, heart disease, and severe lung disease. This trial was approved by the ethics committee of the First Affiliated Hospital, Zhejiang University School of Medicine. All authors had access to the study data and reviewed and approved the final manuscript. All patients signed the written informed consent form before CEUS examination.

A colour Doppler ultrasound diagnostic apparatus (GE company Voluson E8/Parkson company MyLab Class C) was used with a transvaginal probe (frequency 5-9 MHz). All patients underwent TVS before CEUS. After emptying the bladder, the patient underwent TVS, and the sonographers focused on observing and recording whether there were abnormal echoes in the uterine cavity or myometrium and its relationship with surrounding tissues and observing whether there were abnormal echoes in bilateral appendages. CDFI was started, the blood flow distribution in and around the lesion was recorded, and the resistance index (RI) was measured in all patients. Then, the best scanning section of the lesion (that is, the section with the largest diameter of the lesion, which shows the tissue around the lesion to the greatest extent) was selected and switched to contrast mode (contrast/general), which can display a double or single image interface, and the mechanical index (MI) was 0.08 . The contrast agent used was SonoVue. Intravenous channels were established before imaging, contrast media was prepared on site, and $5 \mathrm{ml}$ of saline was added and shaken vigorously to form a milky suspension. A total of $2.4 \mathrm{ml}$ of contrast agent was injected into antecubital vein, the timer was started at the same time, images were continuously collected for 5 minutes in real time, and the dynamic image was stored on the hard drive of the instrument.

Subsequently, we retrospectively collected the clinical data of patients with ITTs diagnosed by surgery and pathology, including age, pregnancy history, main clinical symptoms, type of previous pregnancy, time from diagnosis to the previous pregnancy, serum hCG level, whether there was distant metastasis, and treatment plan. The pathological sections of all patients were interpreted by the deputy chief physician of the pathology department of the institution. At the same time, two sonographers who had worked for more than 5 years analysed the characteristics of the ultrasound and CEUS. If the two opinions were inconsistent, a third doctor with the same qualifications analysed the data to resolve the dispute. Due to the small sample size, statistical analyses were not used.

\section{Results}

Clinical features

A total of 8 patients were diagnosed with ITT during the study, including 4 patients with PSTT and 4 patients with ETT(Table 1). Because 1 patient's lesion (ETT) was located in the appendix area, this patient was not included in the scope of this study. The average age of the patients was 31 years (26 to 44 years), the average pregnancy was 2.27 (1-4), and the parity was 0.91 (0-2). Six patients had a history of amenorrhea, 5 patients had irregular vaginal bleeding, and 1 patient was asymptomatic. The serum hCG level of all patients was elevated, and the average serum hCG level was 8167 IU/L (15.82-55422.2 IU/L). Two patients with distant metastasis underwent ETT..

Ultrasound imaging features

The 7 patients in this study all had single lesions in the uterus

According to the different growth directions of the lesion, the lesions were divided into 3 types: type l, where most of the lesions protruded into the uterine cavity; type II, where the lesions were partly located in the uterine cavity and partly in the muscle layer; and type III, where the lesions were limited in the myometrium. The internal echo of the lesion can be divided into solid and cystic-solid echoes(Table 2).

The 4 patients had PSTT lesion diameters of $1.2-5.3 \mathrm{~cm}$, with an average of $2.8 \mathrm{~cm}$. All of them were heterogeneous solid masses. The boundary between the lesion and the myometrium was not clear, and spheroid formation was not obvious (Figure $1 \mathrm{~A}, \mathrm{~B}$ ). CDFI showed minimal to moderate blood supply to the lesion (Figure $2 A, B$ ). The RI was $0.45-0.55$, with an average of 0.5 . The 3 patients had ETT lesion diameters of $1.7-3.3 \mathrm{~cm}$, with an average diameter of $2.4 \mathrm{~cm}$. Two patients with a cystic-solid echo and 1 patient with a solid isoechoic echo were observed. The boundary of the lesion was clearer, and spheroid formation was more obvious in ETT than in PSTT (Figure 1C). CDFI showed a moderate to abundant blood supply to the lesion (Figure 2C). The RI was 0.5-0.54, with an average of 0.52 .

CEUS perfusion characteristics 
Of the 7 patients with ITTs with CEUS, 2 patients showed diffuse enhancement, and 5 patients showed regional enhancement. One patient had rapid high enhancement in the arterial phase, and 6 patients had slow, equal-slightly high enhancement. One patient had an enhanced clear boundary, and 6 patients had a less clear boundary (Figure 3). In general, there were no significant differences in CEUS between PSTTs and ETTs(Table 2).

Table 1

Clinical features of ITTS

\begin{tabular}{|c|c|c|c|c|c|c|c|c|c|c|}
\hline Case & $\begin{array}{l}\text { Age } \\
\text { (years) }\end{array}$ & $\begin{array}{l}\text { First } \\
\text { diagnosis }\end{array}$ & $\begin{array}{l}\text { Final } \\
\text { diagnosis }\end{array}$ & $\begin{array}{l}\text { Antecedent } \\
\text { pregnancy }\end{array}$ & $\begin{array}{l}\text { Interval } \\
\text { to } \\
\text { diagnosis } \\
\text { (months) }\end{array}$ & Amenorrhea & $\begin{array}{l}\text { Vaginal } \\
\text { bleeding }\end{array}$ & $\beta-$ & $\begin{array}{l}\text { Metastasis } \\
\text { site }\end{array}$ & treatment plan \\
\hline 1 & 28 & $\mathrm{CC}$ & PSTT & $\begin{array}{l}\text { Missed } \\
\text { abortion }\end{array}$ & 13 & + & + & 187.6 & & $\begin{array}{l}\text { Total uterus + } \\
\text { double } \\
\text { fallopian tube } \\
\text { resection; } \\
\text { Chemotherapy }\end{array}$ \\
\hline 2 & 26 & $\begin{array}{l}\text { Biochemical } \\
\text { pregnancy }\end{array}$ & PSTT & $\begin{array}{l}\text { Term } \\
\text { pregnancy }\end{array}$ & 5 & + & + & 170 & & $\begin{array}{l}\text { Total uterus + } \\
\text { double } \\
\text { fallopian tube } \\
\text { resection } \\
\text {;Chemotherapy }\end{array}$ \\
\hline 3 & 28 & $\begin{array}{l}\text { Early } \\
\text { pregnancy }\end{array}$ & PSTT & $\begin{array}{l}\text { Early } \\
\text { pregnancy } \\
\text { abortion }\end{array}$ & 1 & + & + & 1063 & & $\begin{array}{l}\text { Total uterus + } \\
\text { double } \\
\text { fallopian tube } \\
\text { resection; } \\
\text { Chemotherapy }\end{array}$ \\
\hline 4 & 39 & RPOC & PSTT & $\begin{array}{l}\text { Term } \\
\text { pregnancy }\end{array}$ & 5 & + & + & 15.82 & & $\begin{array}{l}\text { Total uterus + } \\
\text { double } \\
\text { fallopian tube } \\
\text { resection }\end{array}$ \\
\hline 5 & 29 & GTN & ETT & $\begin{array}{l}\text { Spontaneous } \\
\text { abortion }\end{array}$ & 12 & + & + & 257.4 & & $\begin{array}{l}\text { Total uterus+ } \\
\text { double } \\
\text { fallopian tube } \\
\text { resection; } \\
\text { Chemotherapy }\end{array}$ \\
\hline 6 & 44 & $\begin{array}{l}\text { Uterine } \\
\text { fibroids }\end{array}$ & ETT & $\begin{array}{l}\text { Term } \\
\text { pregnancy }\end{array}$ & 240 & & & 55422.2 & $\begin{array}{l}\text { Right } \\
\text { ovary } \\
\text { bladder }\end{array}$ & $\begin{array}{l}\text { Total } \\
\text { uterus+double } \\
\text { attachment } \\
\text { resection; } \\
\text { Chemotherapy }\end{array}$ \\
\hline \multirow[t]{2}{*}{7} & 28 & hydatidiform & ETT & hydatidiform & 6 & + & & 53.2 & Right lung & $\begin{array}{l}\text { Total } \\
\text { uterus+double } \\
\text { attachment } \\
\text { resection; } \\
\text { Chemotherapy }\end{array}$ \\
\hline & & & & & & & & & & $\begin{array}{l}\text { Right lower } \\
\text { lobectomy }\end{array}$ \\
\hline
\end{tabular}




\begin{tabular}{|c|c|c|c|c|}
\hline Case & Grayscale ultrasound & $\begin{array}{l}\text { Lesion } \\
\text { type }\end{array}$ & CDFI & CEUS \\
\hline $\begin{array}{l}1 \\
\text { PSTT }\end{array}$ & $\begin{array}{l}\text { Solid mass at the bottom of the uterine cavity, most of } \\
\text { which protrude into the uterine cavity }(2.2 * 2.3 \star 2.2 \mathrm{~cm}) \text {, } \\
\text { unclear boundary }\end{array}$ & प & $\begin{array}{l}\text { moderate } \\
\text { blood flow } \\
\text { signals } \\
\text { PSV: } 26.7 \mathrm{~cm} / \mathrm{s} \\
\text { EDV: } 14.5 \mathrm{~cm} / \mathrm{s} \\
\text { Rl:0.45 }\end{array}$ & $\begin{array}{l}\text { Rapid diffuse enhancement of arterial phase, the } \\
\text { peak intensity is significantly higher than } \\
\text { myometrium, clear boundary }\end{array}$ \\
\hline $\begin{array}{l}2 \\
\text { PSTT }\end{array}$ & $\begin{array}{l}\text { Local echoes of the posterior wall of the myometrium } \\
\text { are enhanced, and some protrude into the uterine cavity, } \\
\text { unclear boundary }\left(1.6^{\star} 1.2 * 1.4 \mathrm{~cm}\right)\end{array}$ & प & $\begin{array}{l}\text { moderate } \\
\text { blood flow } \\
\text { signals } \\
\text { PSV: } 25.6 \mathrm{~cm} / \mathrm{s} \\
\text { EDV: } 11.5 \mathrm{~cm} / \mathrm{s} \\
\text { RI:0.55 }\end{array}$ & $\begin{array}{l}\text { Slow regional enhancement of arterial phase, the } \\
\text { peak is equal to the myometrium, unclear boundary }\end{array}$ \\
\hline $\begin{array}{l}3 \\
\text { PSTT }\end{array}$ & $\begin{array}{l}\text { Solid mass in the uterine cavity with unclear } \\
\text { boundary }(1.7 * 1.0 * 0.7 \mathrm{~cm})\end{array}$ & $\square$ & $\begin{array}{l}\text { minimal blood } \\
\text { flow signals } \\
\text { PSV: } 22.3 \mathrm{~cm} / \mathrm{s} \\
\text { EDV: } 10.5 \mathrm{~cm} / \mathrm{s} \\
\text { RI:0.53 }\end{array}$ & $\begin{array}{l}\text { Slow regional enhancement of arterial phase, the } \\
\text { peak is slightly higher than the myometrium, unclear } \\
\text { boundary }\end{array}$ \\
\hline $\begin{array}{l}4 \\
\text { PSTT }\end{array}$ & $\begin{array}{l}\text { The myometrium of the right side wall has uneven echo, } \\
\text { partially fuller, and some protruding into the uterine } \\
\text { cavity }(4.0 \star 4.3 \star 5.3 \mathrm{~cm}) \text {, unclear boundary }\end{array}$ & प & $\begin{array}{l}\text { minimal blood } \\
\text { flow signals } \\
\text { PSV: } 19.6 \mathrm{~cm} / \mathrm{s} \\
\text { EDV: } 9.8 \mathrm{~cm} / \mathrm{s} \\
\text { RI:0.5 }\end{array}$ & $\begin{array}{l}\text { Slow diffuse enhancement of arterial phase, the } \\
\text { peak is slightly higher than the myometrium, unclear } \\
\text { boundary }\end{array}$ \\
\hline $\begin{array}{l}5 \\
\text { ETT }\end{array}$ & $\begin{array}{l}\text { Cystic solid mass on the posterior wall of the } \\
\text { myometrium with clear boundary }\left(1.8^{*} 1.7^{*} 1.8 \mathrm{~cm}\right)\end{array}$ & प & $\begin{array}{l}\text { abundant } \\
\text { blood flow } \\
\text { signals } \\
\text { PSV: } 28.5 \mathrm{~cm} / \mathrm{s} \\
\text { EDV: } 13.4 \mathrm{~cm} / \mathrm{s} \\
\text { Rl:0.53 }\end{array}$ & $\begin{array}{l}\text { The solid part shows slow regional enhancement in } \\
\text { the arterial phase, the peak is slightly higher than } \\
\text { the myometrium, unclear boundary, no } \\
\text { enhancement of cystic part }\end{array}$ \\
\hline $\begin{array}{l}6 \\
\text { ETT }\end{array}$ & 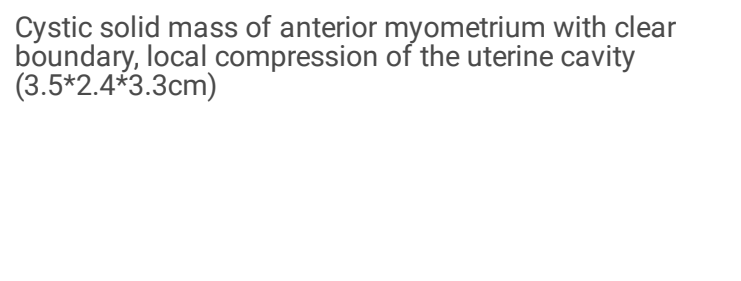 & प & $\begin{array}{l}\text { moderate } \\
\text { blood flow } \\
\text { signals } \\
\text { PSV: } 26.4 \mathrm{~cm} / \mathrm{s} \\
\text { EDV: } 12.1 \mathrm{~cm} / \mathrm{s} \\
\text { Rl:0.54 }\end{array}$ & $\begin{array}{l}\text { The solid part shows a slow regional enhancement } \\
\text { in the arterial phase,the peak is slightly higher than } \\
\text { the myometrium, unclear boundary, no } \\
\text { enhancement of cystic part }\end{array}$ \\
\hline $\begin{array}{l}7 \\
\text { ETT }\end{array}$ & $\begin{array}{l}\text { Solid mass of posterior wall of myometrium, with clear } \\
\text { boundary, partial protrusion into the uterine cavity } \\
(2.3 * 1.9 * 2.8 \mathrm{~cm})\end{array}$ & प & $\begin{array}{l}\begin{array}{l}\text { moderate } \\
\text { blood flow } \\
\text { signals }\end{array} \\
\text { PSV: } 21.6 \mathrm{~cm} / \mathrm{s} \\
\text { EDV: } 10.3 \mathrm{~cm} / \mathrm{s} \\
\text { Rl:0.52 }\end{array}$ & $\begin{array}{l}\text { Slow regional enhancement of arterial phase, The } \\
\text { peak is equal-slightly higher to the myometrium } \\
\text {,unclear boundary }\end{array}$ \\
\hline
\end{tabular}

\section{Discussion}

In 1984, Young and Scully ${ }^{[16]}$ studied and summarized 22 patients with GTN reported worldwide. Kurman confirmed by immunohistochemistry that PSTT originated from intermediate trophoblasts ${ }^{[17]}$. In 1998, Shih and Kurman ${ }^{[18]}$ proposed the name ETT for an ITT with alternative histological and immunohistochemical characteristics. In 2003, the WHO classification of ETT as a single morphological tumour was composed of intermediate trophoblast cells that are very similar to smooth chorion ${ }^{[19]}$. In 2014, the WHO classification of gynaecological tumours classified GTN into CC, PSTT 
and ETT subtypes, and the latter two are collectively referred to as ITTs. As ITTs are relatively highly differentiated and are not sensitive to conventional chemotherapy regimens, surgical resection is the main treatment option, and early detection is essential for clinical treatment and improving prognosis.

According to previous reports ${ }^{[20]}$, ITTs mainly occur in women of childbearing age and can be secondary to a variety of pregnancy outcomes and are often misdiagnosed as uterine fibroids, cervical cancer, CC or other pregnancy-related diseases. Because tumour cells secrete human placental lactogen, leading to hyperprolactinemia, amenorrhea and vaginal bleeding are seen in $71.3 \%$ and $35.2 \%$ of patients, respectively ${ }^{[21]}$. The clinical characteristics of this study cases are basically in line with previous reports. Compared with that of other GTNs, the serum hCG level of ITT patients is generally low $(<1000-2500 \mathrm{IU} / \mathrm{L})$, but there are still approximately $10 \%$ of patients with normal serum hCG levels or a few patients with serum hCG levels as high as $100000 \mathrm{IU} / \mathrm{L}$. Therefore, there is no specific performance of serum hCG levels ${ }^{[21]}$. In this group of patients, there were 6 patients with serum hCG levels $<1000-2500 \mathrm{IU} / \mathrm{L}$, and the serum hCG level of 1 patient was $55422.2 \mathrm{IU} / \mathrm{L}$. It has been reported that when a patient with ITT has distant metastasis, the serum hCG level is usually higher than that of nonmetastatic patients ${ }^{[22]}$. However, in this study, the serum hCG level of 1 patient with lung metastasis was not high (53.2 IU/L), and the serum hCG level of the other patient with ovarian and bladder metastases was significantly high (55422.2 IU/L). Therefore, we believe that to determine whether the serum hCG level can be used as one of the indicators for monitoring ITT recurrence or metastasis, a large sample data analysis is needed.

Due to the rare disease and lack of specific clinical manifestations, the preoperative diagnosis of ITT is very difficult. The current clinical diagnosis of ITT requires a comprehensive judgement based on the serum hCG level, pathology and imaging. Among them, imaging diagnosis has important value. Since the tissue composition in ITT lesions is not specific, computed tomography and magnetic resonance imaging are not very helpful in the differential diagnosis of ITT ${ }^{[23]}$. Transvaginal colour Doppler ultrasound can make a preliminary assessment of the size, location, myometrium invasion, relationship with surrounding tissues, and blood supply of the lesion. However, this technology has a poor ability to show low-velocity blood flow and has a certain angle dependence, which cannot meet the requirements for imaging tumour neovascularization. It is difficult to make further diagnoses for lesions that are unclear from the surrounding normal tissues and limited CDFI blood flow signals. CEUS is currently the latest method to display vascular perfusion. CEUS evaluates the pathological basis of intratumour blood perfusion based on ultrasound contrast agents that can well display the distribution of microcirculation in the tumour and reflect the abundance of new blood vessels inside the tumour. CEUS can significantly improve the ability to display small blood vessels and low-speed blood flow in tumours. However, the application of CEUS in diagnosing ITT has not yet been reported.

PSTT cells separate each muscle cell or a group of muscle cells, infiltrate these cells, and often involve the endometrium ${ }^{[24]}$ (Figure 1D). Unlike invasive hydatidiform or CC, which exhibits extensive erosion of blood vessels, approximately $1 / 2$ of PSTT presents as solid hypoechoic or isoechoic lesions, and most of the blood flow signals are minimal or moderate. In this group of cases, we found that PSTTs all originated from the myometrium. Most of the lesions are not clearly demarcated from the surrounding tissues, and there is no obvious spheroid formation. This ultrasound feature is also consistent with the pathological changes in PSTT tumour cells showing infiltration. When PSTT lesions show cystic or cyst-solid echo, CDFI shows abundant blood flow signals or explores the blood flow spectrum of arteriovenous fistula, which is often related to the expansion of blood vessels in the lesion and even the formation of arteriovenous fistula. Zhou et al. reviewed 14 cases of PSTT ultrasound images and divided them into 3 types ${ }^{[12]}$. Among them, cystic lesions in the myometrium with abundant blood flow signals were classified as type III. They believed that this type of manifestation is difficult to distinguish from invasive hydatidiform, CC, and even RPOC. ETT is generally in the form of swelling nodules with clear boundaries, and some of them may also infiltrate. Tumour cells are adjacent to cellulose, transparent glass-like material and necrotic areas, forming a typical "map-like" appearance, and can replace the cervix membrane ${ }^{[24]}$ Figure 1EX. PSTT is more prone to vascular infiltration than ETT, but extensive necrosis is usually present in ETT. In this study, the boundaries of the 2 ETT lesions were clearer, and the spheroid sensation was more obvious than that of PSTT. This feature was closely related to the swelling growth pattern of tumour cells. CDFI showed moderate or abundant blood flow signals in 3 ETTs. QIN et al. retrospectively analysed the ultrasound images of 12 patients with ETT and concluded that compared with other GTNs, there were more new blood vessels around the tumour than in the area within the tumour ${ }^{[14]}$. Therefore, CDFI showed abundant Doppler around the lesion. Blood flow signals are a strong basis for distinguishing ETTs from other GTNs. However, some studies believe that not all ETTs have a blood flow that is characteristic, and a small number of ETTs can also manifest with minimal blood flow signals ${ }^{[13]}$. In this study, ETT blood flow signal performance did not reflect this feature, and the overall performance was not significantly different from that of PSTT.

The trophoblasts of normal early pregnancy and benign trophoblastic tumours erode only the blood vessels of the endometrium and will not cause changes in the vascular architecture of the myometrium. This feature is the pathological basis for the observation of uterine blood flow status and circulatory dynamics changes by CEUS and the diagnosis of benign and malignant trophoblastic diseases ${ }^{[25]}$. In CEUS, ultrasound contrast agent microbubbles can enter the myometrial blood vessels from the myometrium into the abnormal sinusoids formed by the destruction of trophoblast cells or the new blood vessels formed by the replacement of vascular endothelial cells by trophoblasts. Since there is no report on CEUS for diagnosing ITT, this study refers to the classification of CEUS imaging of the liver, thyroid, and breast, combined with the pathological characteristics of ITT, and observed the lesions from four aspects: enhancement mode, enhancement boundary, enhancement time and enhancement intensity. The CEUS mode of the lesion was divided into the diffuse enhancement type (all the lesion area was enhanced or the internal nonenhanced area was cracked) and regional enhancement type (part of the lesion was enhanced, and the internal nonenhanced area was patchy). The contrast enhancement boundary was divided into clear and unclear. The enhancement intensity was divided into high enhancement and equal-slightly high enhancement. Contrast enhancement time was divided into arterial phase rapid enhancement and slow enhancement. 
In this study, there were 5 patients with ITT with regional enhancement and 2 patients with diffuse enhancement. Regional enhancement was more common in patients with ETT. The reason for the different enhancement modes of contrast-enhanced ultrasound may be that the contrast medium microbubbles enter into the abnormal blood sinus or neovascularization of the myometrium and then develop rapidly, showing diffuse enhancement, while the different blood vessels, necrotic tissue proportions and necrotic sites in the tumour show different enhancement modes. However, ETT vascular invasion is less common than PSTT, and the pathological characteristics of ETT more prone to extensive necrosis may be the main reason for the regional enhancement of ETT in this study.

Tumour cells invade blood vessels and change their structure. When the number of blood vessels in the lesion increases or larger sinusoids form, the resistance of the vascular bed decreases, and contrast agent microbubbles can quickly enter the lesion, showing rapid high enhancement. At the same time, because of the microbubbles in the lesion area earlier than the myometrium, the lesion area was almost fully enhanced before the myometrium. There is a significant difference between the two, which is also the reason for the clearness of the lesion boundary after angiography. The characteristic of PSTT infiltration is that tumour cells separate each smooth muscle fibre or several groups of muscle fibres, and single, cord, island or sheet tumour cell infiltration can be seen between muscle fibre bundles, so more than half of PSTTs are solid hypoechoic or isoechoic lesions with minimal or moderate blood flow signals. ETT cells resemble islands and are located in vitreous and necrotic tissues. Small blood vessels can be seen in the lesion, but vascular infiltration is rare. In this study, CEUS of ITTs mainly focused on the arterial phase and slow, equal-slightly high enhancement. The reason may be that although ITT cells invade blood vessels and change their structure, due to their pathological infiltration characteristics, the number of new blood vessels formed in the lesions or the size of blood sinuses are far less than those of other GTNs, resulting in an insignificant reduction in vascular bed resistance, and contrast agent in microvesicles cannot enter the lesion quickly. In this group of patients, except for 1 patient with rapid and high enhancement of PSTT, the blood flow RI of the lesion was 0.45 , and the blood flow RI of the other 6 lesions were all higher than 0.5 , which was basically consistent with the performance of CEUS. This can also explain why the greyscale ultrasound appearance of PSTTs and ETTs is basically the same as the growth pattern of tumour cells, but most of the lesion boundaries in CEUS are not clear.

As the rarest GTN, ITT usually has low serum hCG immune activity in serum, so it needs to be distinguished from other types of GTNs, such as early CC, and some diseases that can secrete a small amount of serum hCG, such as RPOC. According to previous reports [26], CEUS of the CC showed no enhancement in the central area and rapid and high-enhanced ring-shaped enhancement around the periphery. Invasive hydatidiform lesions showed reticular enhancement. CEUS of RPOC was mainly enhanced in the region, but there were many blood clots inside the lesion, and the area without enhancement was more than $1 / 2$ of the area of the lesion. In this study, the ITT enhancement mode was mainly regional enhancement, and the arterial phase showed slow, equal-slightly high enhancement. CEUS performance has a certain specificity, which is believed to be helpful in distinguishing other types of GTNs and other diseases.

The downside is that this research is a retrospective analysis. The sample size is small, which has a certain impact on the research design. The accuracy of the research results needs to be further verified by increasing the sample size. During the study, we observed that the venous phase of the lesion subsides more slowly than the myometrium. However, due to the short delay phase of the existing contrast agent (SonoVue), the lesion can hardly be displayed approximately 5 minutes after the injection of the contrast agent. Therefore, there is no complete observation or study of the contrast intravenous phase of the lesion. In future research, we plan to use a contrast agent (Sonazoid) with a delay phase of up to 30 minutes for ultralong development. We also plan to carry out a multicentre collaborative research study to increase the sample size and look forward to having a deeper understanding of the CEUS characteristics of ITTS.

\section{Conclusions}

In this study, we found that the lesion location, size, and echo of ITTs were not significantly specific compared with those of other GTNs. ITTs appear as solid masses or cystic-solid masses, and CDFls show that the blood flow signal can appear from minimal to abundant. Therefore, it is very difficult to diagnose ITTs by colour Doppler ultrasound alone. We found that the ITT enhancement mode was mainly regional enhancement, and the arterial phase showed slow, equal-slightly high enhancement. We believe that the CEUS performance of ITTs has a certain specificity compared with other GTNs, combined with clinical features that can effectively improve the accuracy of diagnosing ITTs.

\section{Abbreviations}

GTN: Gestational trophoblastic neoplasia; ITTs: Intermediate trophoblastic tumours; PSTT: Placental-site trophoblastic tumour; ETT: Epithelioid trophoblastic tumour; CEUS: Contrast enhanced ultrasonography; CDFI: Colour Doppler ultrasound image; RPOC: Retained products of conception; CC: Choriocarcinoma; TVS: Transvaginal ultrasonography; RI: Resistance index.

\section{Declarations}

\section{Ethics approval and consent to participate}

This trail was approved by the ethics committee of the First Affiliated Hospital, Zhejiang University School of Medicine. All authors had access to the study data and reviewed and approved the final manuscript. All methods were performed in accordance with the relevant guidelines and regulations. Both the enrolled patients had informed consent for the procedure. All patients signed the written informed consent form before CEUS examination. 


\section{Consent to publish}

The authors certify that they have obtained all appropriate patient consent forms. In the form all patients have given their consents for their images and other clinical information to be reported in the journal. All patients understands that their name and initial will not be published and due efforts will be made to conceal their identity, but anonymity cannot be guaranteed.

\section{Availability of data and materials}

All data generated or analysed during this study are included in this published article .

\section{Competing interests}

The authors declare that they have no competing interests.

\section{Funding}

This study was supported by the National Natural Science Foundation of China(81971632)

\section{Authors' contributions}

XDZ drafted the manuscript, collected the data, and reviewed the literature. YH collected the data .LYZ performed the histological examinations and reviewed the manuscript. TAJ provided academic help. NO critically reviewed the manuscript. All authors confirmed and approved the final manuscript.

\section{Acknowledgements}

The authors thank Dr. LinYu Zhou and Dr. Yin Hu for helpful advice and Professor TianAn Jiang of the Ultrasound Medicine Department for discussion and manuscript revision.

\section{References}

1. Angiolo Gadducci,Silvestro Carinelli, et al.Placental site trophoblastic tumor and epithelioid trophoblastic tumor:Clinical and pathological features, prognostic variables andtreatment strategy. Gynecologic Oncology .153 (2019): 684-693.

2. Hyman DM, Bakios L,et al. Placental site trophoblastictumor: Analysis of presentation, treatment, and outcome[J]. Gynecol Oncol, 2013, 129:58-62.

3. Keser SH, Kokten SC, Cakir C, et al. Epithelioid trophoblastic tumor [J]. Taiwan J Obstet Gynecol, 2015, 54:621-624.

4. A.J. Papadopoulos, M. Foskett, M.J. Seckl, I. McNeish, F.J. Paradinas, H. Rees, E.S. Newlands, Twenty-five years' clinical experience with placental site trophoblastic tumors, J. Reprod. Med. 47 (2002) 460-464.

5. H.Y. Zhang, X.N. Yue, et al. Placental site trophoblastic tumor presented with vaginal metastasis, Int. J. Clin. Exp. Med. 8 (2015) $2993-2997$.

6. S. Ayas, A. Gurbuz, A. Karateke, Placental site trophoblastic tumor with multiple metastases and complete response to salvage BEP regimen: a case report and review of the literaure, Med. Oncol. 26 (2009) 96-100.

7. Jiang Fang, Xiang Yang. Deeper Understanding of Epithelioid Trophoblastic Tumor. Med J PUMCH,2018,9(1): 31-35.

8. N.S. Horowitz, D.P. Goldstein, R.S. Berkowitz, Placental site trophoblastic tumors and epithelioid trophoblastic tumors: biology, natural history, and treatment modalities, Gynecol. Oncol. 144 (2017) 208-214.

9. Caspi B, Elchalal U, Dgani R,et al. Invasive mole and placental site trophoblastic tumor. Two entities of gestational trophoblastic disease with a common ultrasonographic appearance. J Ultrasound Med 1991; 10:517-519.

10. L Savelli, P Pollastri, M Mabrouk, et al.Placental site trophoblastic tumor diagnosed on transvaginal sonography.Ultrasound Obstet Gynecol. 2009 Aug;34(2):235-6.

11. Y. ICHIKAWA, T. NAKAUCHI, et al.Ultrasound diagnosis of uterine arteriovenous fistula associated with placental site trophoblastic tumor.Ultrasound Obstet Gynecol 2003; 21: 606-608.

12. Y. ZHOU, H. LU,et al. Sonographic characteristics of placental site trophoblastic tumor.Ultrasound Obstet Gynecol 2013; 41: 679-684.

13. Okumura M, Fushida K, et al. Sonographic appearance of gestational trophoblastic disease evolving into epithelioid trophoblastic tumor[J]. Ultrasound Obstet Gynecol. 2010,36:249-251.

14. Jiale Qin, Weiwen Ying,et al. A Well-Circumscribed Border with Peripheral Doppler Signal in Sonographic Image Distinguishes Epithelioid Trophoblastic Tumor from Other GestationalTrophoblastic Neoplasms. PLoS One. 2014 Nov 14;9(11):e112618.

15. Mulvagh SL,DeMaria AN,et a1.Contrast echocardiography current and future applictions. [J] J Am Soc Echocariogr'2000,13:331-342.

16. Young RH, S cu lly RE. Placental site trophoblastic tumor:current status. C lin ObstetGynecol. 1984, 27:248-258.

17. Kurman RJ. The morphology, biology, and pathology of intermediate trophoblast:a look back to the present .Hum Pathol.1991, 22:847-855.

18. Shih I M, Kurman RJ. Epithelioid trophoblastic tumor: a neoplasm distinct from choriocarcinoma and placental site trophoblastic tumor simulating carcinoma. Am J Surg Pathol, 1998, 22:1393-1403. 
19. Tavassoli FA, Devilee P. World Health Organization classification of tumours. Path ology and genetics of tumours of the breast and female genital organs. Lyon:IARC press, 2003. 251-254.

20. Jordan S, Randall LM, et al. Differentiating squamous cell carcinoma of the cervix and epithelioid trophoblastic tumor [J]. Int J Gynecol Cancer. 2011, 21: 918-922.

21. Zhao J, Lv WG, Feng FZ, et al. Placental site trophoblastic tumor: A review of 108 cases and their implications for prognosis and treatment [J]. Gynecol Oncol. 2016, 142:102-108.

22. Zheng Ju,Xie Hongning,et al.Clinical features and sonographic characteristics of intermediate trophoblastic tumor. Oncoradiology,2017,Vol.26,No.3:188-192.

23. Kageyama S, Kanoto M, Sugai Y, et al. MR imaging of uterine epithelioid trophoblastic tumor: a case report[J]. Magn Reson Med Sci, 2016, 15:411415.

24. Li Bao-zhu, Zhu Li,et al. Clinicopathologic study of tumors of intermediate trophoblasts.Chin J Pathol, December 2006, V ol 35, No. $12: 722-726$.

25. Zygmunt M, Herr F, et a1. Angiogenesis and vasculogenesis in pregnancy. [J] Eur J Obstet Gynecol Reprod Biol. 2003 Sep 22;110 Suppll:S10-8.

26. Zhang Lianhua,Wu Xiulan ,et al. Application of contrast-enhanced ultrasound in the diagnosis of uterine gestational trophoblast lesions. Journal of Medical Imaging .2017, 27(2):311-315.

\section{Figures}

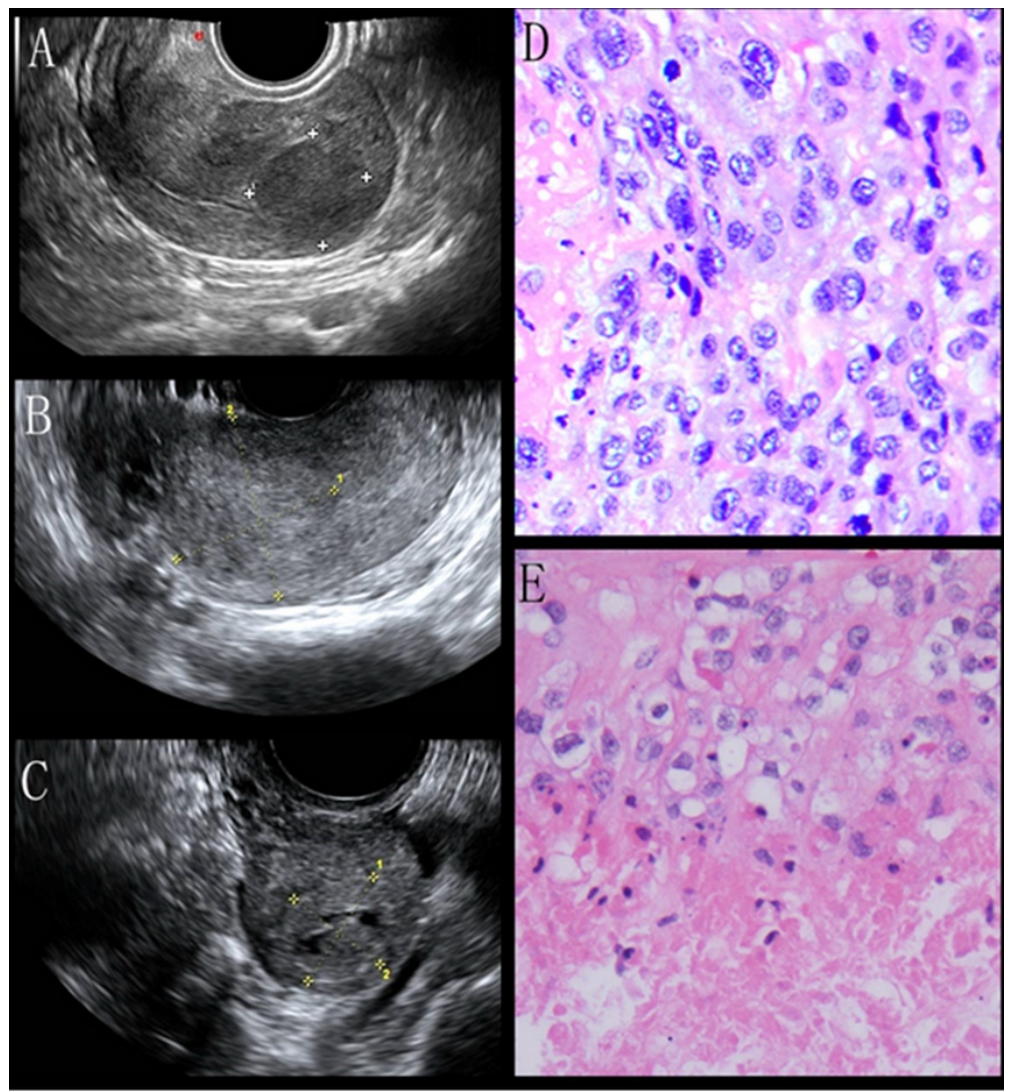

Figure 1.A.PSTT-Most of the solid masses protrude into the uterine cavity and the boundary is not clear. B.PSTT-The solid mass is located in the myometrium, the boundary is not clear. C.ETT-The cystic -solid mass is located in the myometrium, the boundary is clear. D.PSTT-Haematoxylin-eosin staining by microscopy, magnification 400x(C). E.ETT-Haematoxylin-eosin staining by microscopy, magnification $400 x(C)$.

\section{Figure 1}

See image above for figure legend 


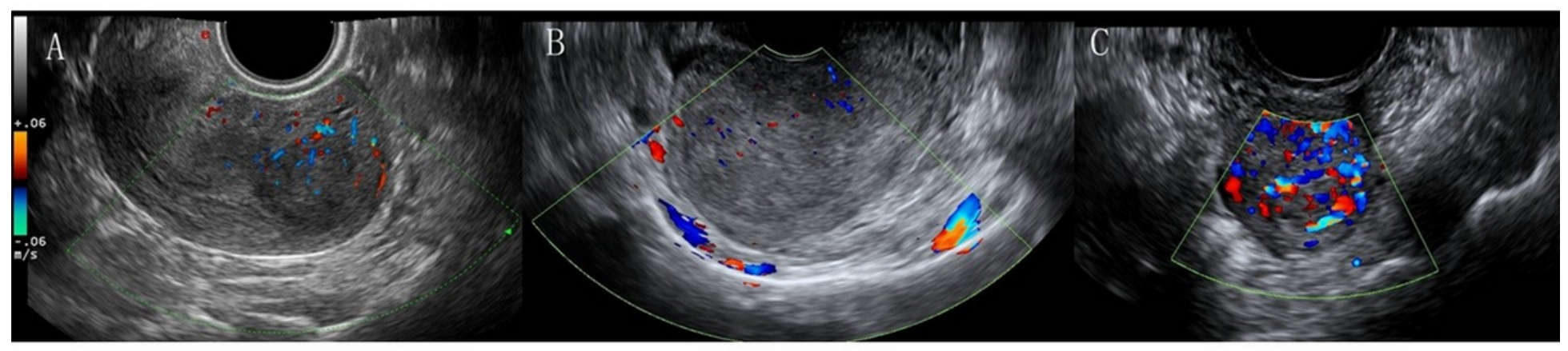

Figure 2.A. PSTT-The solid mass with moderate blood flow signal. B.PSTT-The solid mass with minimal blood flow signal. C.ETT-The cystic-solid mass with abundant blood flow signal.

Figure 2

See image above for figure legend

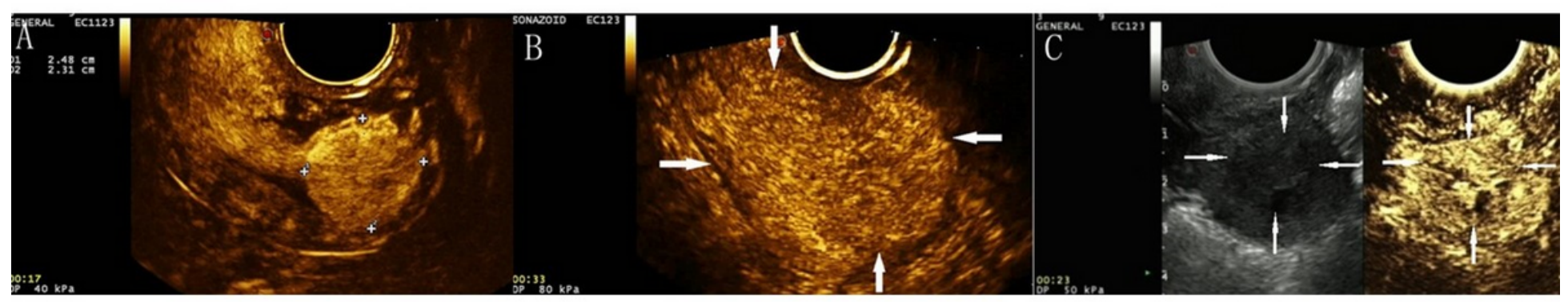

Figure 3. A.PSTT-A rapid high enhancement in arterial phase, the contrast enhancement mode is diffuse enhancement and the boundary clear. B.PSTT-A slow,equal-slightly high enhancement in arterial phase. The contrast enhancement mode is diffuse enhancement and the boundary is unclear. C. ETT-A slow,equal-slightly high enhancement in arterial phase. The contrast enhancement mode is regional enhancement and the boundary is unclear.

Figure 3

See image above for figure legend 